I Universidade Federal do Rio de Janeiro (UFRJ),

Rio de Janeiro, RJ, Brasil

glauciavboas@gmail.com

https://orcid.org/0000-000I-5357-740X

Glaucia Villas Bôas'

\title{
80 ANOS DE CIÊNCIAS SOCIAIS NA UFRJ: RELEMBRANDO O PIONEIRISMO DOS PROJETOS GRUPOS ECONÔMICOS (1962) E TRABALHADORES CARIOCAS (1987)
}

Avaliar o significado da experiência intelectual advinda da prática de ensino e pesquisa em ciências sociais, que se desenvolve há 80 anos, primeiro na Faculdade Nacional de Filosofia (FNFI) e depois no atual Instituto de Filosofia e Ciências Sociais (IFCS) da Universidade Federal do Rio de Janeiro, não é tarefa de pouca monta. Que medida poderia ser usada para saber de sua importância na vida e formação de tantos professores, na repercussão de sua docência em inúmeros jovens, na imaginação e na pesquisa, nos efeitos simbólicos da produção de conhecimentos? Este pequeno registro de pesquisa certamente não responderá a essas questões, mas pretende dar início a um esforço de memória que possibilite mais adiante reunir alguns aspectos da história daquela (já longa) atividade intelectual na cidade do Rio de Janeiro para que se possa então pensar em avaliar seus efeitos.

Poucos estudantes e professores conhecem os projetos de pesquisa pioneiros realizados no campo das ciências sociais no IFCS, em um intervalo de 20 anos, no qual se intercala a ditadura militar (I964-I985). Um deles, sobre os grupos econômicos multibilionários, foi realizado de 1962 a I967, no antigo Instituto de Ciências Sociais da Universidade do Brasil, incorporado pelo IFCS em I967; o outro, Trabalhador carioca: produção e reprodução da classe trabalhadora do estado do Rio de Janeiro (I987 a I992), foi iniciativa de peso para alargar o conhecimento da classe trabalhadora brasileira bem como para a criação do Programa de Pós-Graduação em Sociologia e Antropologia. Não há 
melhor ocasião do que os festejos dos 80 anos de ciências sociais no IFCS para relembrar esses dois empreendimentos, ressaltando tanto sua repercussão nos debates sobre os temas do capital e do trabalho quanto seus efeitos na construção institucional das ciências sociais na cidade do Rio de Janeiro.

Uma das primeiras iniciativas para criar um instituto de pesquisa e formação de pesquisadores, no âmbito das ciências sociais na Universidade do Brasil, foi o Instituto de Ciências Sociais. Nem é preciso dizer que à época não existia um sistema de pós-graduação no Brasil. As instituições voltadas exclusivamente para a pesquisa eram raras. No Rio de Janeiro funcionavam o Centro Brasileiro de Pesquisa Educacionais, órgão do Instituto Nacional de Pesquisas Educacionais, criado em I952, e o Centro Latino Americano de Pesquisas em Ciências Sociais, fundado em I957, por recomendação da Unesco, que o financiou integralmente durante dez anos. Embora se tratasse de um órgão do governo brasileiro, a Unesco apoiou também notadamente o CBPE, fosse mediante financiamento, fosse por meio de recursos para a vinda e estada de cientistas sociais estrangeiros naquelas instituições, a exemplo de Bertram Hutchinson, Herbert Blumer e Gino Germani, entre outros (Amorim, I999: 33-35). O CBPE e o CLAPCS abriram suas portas para pesquisadores cariocas e de outras cidades brasileiras, sendo bem conhecidas, nos meios intelectuais e acadêmicos, suas bibliotecas atualizadas e suas publicações na Revista Educação e Ciências Sociais e na Revista América Latina. Era notória a internacionalização de suas atividades.

Diferentemente daqueles centros de pesquisa e formação, o ICS, criado em I958, depois de um debate de sete anos no Conselho Universitário, era um instituto de pesquisa, vinculado à Faculdade Nacional de Filosofia, à Faculdade Nacional de Direito, à Faculdade de Ciências Econômicas e ao Museu Nacional por intermédio de sua Divisão de Antropologia. O Instituto se distinguia também dos centros de pesquisa que começavam a surgir em outras áreas do conhecimento, na antiga Universidade do Brasil, por não estar vinculado a uma cátedra específica. O Instituto foi de fato experiência única em sua época. Integraram seu Conselho Diretor Evaristo de Moraes Filho, Luiz de Aguiar Costa Pinto, Luiz de Castro Faria, Victor Nunes Leal, Roberto Cardoso de Oliveira e Marina São Paulo de Vasconcellos, entre outros professores. O ICS recebia recursos da universidade.

Nas palavras de Gilberto Velho (I 997), em homenagem a Maurício Vinhas por ocasião de sua morte (Anuário Antropológico, I996), o ICS abrigou um dos projetos mais ambiciosos sobre grupos econômicos e condições institucionais da industrialização brasileira. Coordenada por Maurício Vinhas de Queiroz, a pesquisa identificou pela primeira vez os grupos econômicos multibilionários brasileiros e estrangeiros instalados no país, desvendando a história de sua acumulação originária. O volume de material recolhido pelo grupo de pesquisadores é surpreendente: materiais impressos de várias origens - tais como relatórios de diretoria, balanços, contas de lucros e perdas, atas de assembleias 
gerais publicadas nos Diários Oficiais, além de dados do IBGE, Ministério da Fazenda, BNDE e Ministério da Indústria, que se somaram a entrevistas com economistas, políticos e especialistas em assuntos econômicos. Em I962, ano de início do projeto, já haviam sido cadastradas 6.300 empresas dos estados da Guanabara, Minas Gerais, São Paulo e Rio de Janeiro, além de um levantamento de indústrias em áreas com menor desenvolvimento industrial, como Paraná, Santa Catarina, Rio Grande do Sul e Amazônia, e outras situadas no Norte e no Centro-Oeste (Revista do Instituto de Ciências Sociais, Seção Noticiário, I962).

Ao ampliar-se o escopo do trabalho durante as primeiras atividades, ${ }^{\mathrm{I}}$ foi necessário dividir a pesquisa em três grupos: Grupos Econômicos Nacionais, com a participação de Luciano Martins de Almeida, Alzira Abreu e Maria Luíza Carvalho Proença; Grupos Bilionários Estrangeiros, com José Antônio Pessoa de Queiróz e Rosélia Perissé; e Grupos Multibilionários Nacionais e Estrangeiros, com Maurício Vinhas de Queiroz e Maria Stella Amorim. Maurício Vinhas de Queiroz decidiu não estabelecer a priori um conceito de grupos econômicos, trabalhando com uma definição ampla como ponto de partida:

Entendemos por grupo econômico todo conjunto relativamente poderoso de empresas interligadas pelo capital e/ou pelo poder de decisão de dirigentes comuns, sempre que os vínculos existentes entre as mesmas sejam mais fortes do que aqueles porventura mantidos com outros grupos ou empresas isoladas. Compreende-se que só um conjunto "relativamente poderoso" é que poderia ser considerado grupo econômico; [...] Praticamente, vimos considerando "relativamente poderoso" todo o agrupamento de empresas entre as quais exista uma - no mínimo - cujo capital próprio seja igual ou superior a 50 milhões de cruzeiros (Queiroz, I962: I57-I58; grifos no original).

Dois anos depois do início da pesquisa, em I964, o coordenador tinha em mãos três minuciosos relatórios, publicados em I 965 pela Revista do Instituto de Ciências Sociais e assinados por ele, Luciano Martins e José Antônio Pessoa de Queirós, respectivamente. Um quarto artigo, de autoria de Vera Werneck, explicava a utilização do método estatístico na análise de dados do projeto. Naqueles relatos não escapa à atenção do leitor o cumprimento da promessa do coordenador de "estudar o grau de patrimonialização ou burocratização" na estrutura interna das empresas (Queiroz, I962: I92).

A problematização das condutas "tradicionais" versus condutas "modernas", tão presente no horizonte das ciências sociais brasileiras, aparece nos trechos transcritos abaixo, que evidenciam I) o envolvimento das relações familiares e pessoais na administração dos negócios multibilionários dos empresários brasileiros, em contraste com o modus operandi das empresas estrangeiras administradas por gerentes; e 2) a heterogeneidade e diversificação dos investimentos dos grupos econômicos nacionais.

Família empresarial e grupo econômico

Todo grupo econômico estrangeiro é por definição gerencial, isto é, dirigido por gerentes ou diretores profissionais, uma vez que os seus proprietários não se encontram no país. 
Já o mesmo não ocorre com os grupos nacionais. Aqui existe com muita frequência uma fusão entre a figura do empresário e a do proprietário, e a família deste ocupa na estrutura de negócios um lugar tão significativo que podemos, quando nos referimos a esses conjuntos de empresas - falar de grupos nitidamente familiais. Analisaremos adiante os casos discrepantes, que podem ser considerados como tipos excepcionais ou de transição. Importa desde já observar que na maior parte dos casos não existe contudo um padrão único e geral de relações entre a família empresarial e o grupo econômico.

Sem dúvida, nos casos mais frequentes a família e as parentelas do empresário desempenham papel importante no controle e administração de firmas do grupo. Todavia, no que diz respeito pelo menos aos grupos multibilionários, o empresário e seus familiares aparecem acompanhados sempre, nos cargos de direção das empresas e em seu controle acionário, por homens de confiança, diretores profissionais e técnicos que não pertencem à família. Por mais que varie de grupo para grupo o número e o significado dos elementos extrafamiliais, a sua participação nunca está ausente.

Estabelecidas essas ressalvas, verifica-se que alguns grupos nacionais multibilionários são caracterizadamente unifamiliais. Nesses casos, indivíduos de uma determinada família, centralizada em torno de seu chefe reconhecido, atuam em posições dominantes nas diretorias e nas listas de acionistas. Esses grupos unifamiliais podem ser mais ou menos rigidamente hierarquizados. No grupo Matarazzo, por exemplo, o Conde Francisco Matarazzo Júnior ocupa o cargo de diretor-presidente em 25 empresas, das quais seus filhos Eduardo e Ermelindo são sempre vice-presidentes, gerentes ou diretores-administrativos. Só poucas firmas do grupo têm outros diretores que não os membros da família. Já no grupo Moreira Salles, também unifamilial, os irmãos João e Walter ocupam em várias firmas lugares que se equivalem em termos de prestígio, e há um número relativamente grande de outras firmas nas quais não aparece como diretor nenhum membro da família; em outras palavras, determinados homens de confiança têm aqui papel de relevo.

Outro padrão organizacional é representado pelos grupos multifamiliais. Neles, de maneira muito característica, várias famílias nucleares, aparentadas ou não entre si, giram em torno de uma outra que detém a parte estratégica dos controles acionários e os mais importantes cargos de decisão. No grupo Almeida Prado, que pertence a esse tipo, a família que lhe dá o nome fica naturalmente no centro do sistema, e em sua volta, ocupando posições de menor destaque, como associados menores, aparecem as famílias Alves de Lima, Vieira da Cunha, Assumpção, Souza Dantas, Gomes dos Reis, Almedia Junqueira, Oliveira Adams, etc. (Queiroz, I962: 70-7I).

O Quadro XVII tem o intuito apenas de dar uma ideia da prevalência de diretores enviados pela matriz, ou recrutados no Brasil, entre os grupos estrangeiros da amostra. A análise efetuada não pretende que se possa quantificar a variável em questão, mas apenas estabelecer, em linhas gerais, a maior ou menor tendência dos grupos estrangeiros de recrutarem no país seus gerentes, inclusive diferenças entre americanos e não americanos a esse respeito. Cerca de $60 \%$ dos grupos recrutam seus gerentes principalmente nos países de origem dos capitais controladores do grupo, sendo maior a proporção dos grupos americanos que confiam 
a administração de seus interesses no Brasil a elementos locais. Essa maior "nacionalização" das diretorias dos grupos americanos em confronto com os não americanos parece se relacionar com a menor possibilidade que têm os gerentes de grupos americanos de influir na "policy" (estabelecimento das diretrizes básicas e gerais a serem seguidas pelo grupo no Brasil) adotada com relação aos interesses do grupo situados no país (Queirós, I965: I68).

Quanto à heterogeneidade e "dispersão" dos investimentos dos grupos bilionários nacionais, Luciano Martins afirma que, no geral, podem ser atribuídas à fase do desenvolvimento, que apresenta possibilidades diversificadas de investimentos. O caso do grupo Abdalla é ilustrativo daquelas características:

Um caso extremamente significativo seria, por exemplo, o do grupo Abdalla. Este grupo dispõe entre outras das seguintes empresas: I fábrica de celulose, I fábrica de papel, 3 empresas têxteis, 2 bancos, I fábrica de potassa e produtos químicos, I estrada de ferro, I fábrica de cimento, I agroindustrial. [...] as informações que sobre a questão recolhemos parecem indicar que parte desses investimentos foi iniciada praticamente na mesma época, entre os anos de 45 e 55 .

$[\ldots]$

Além da causa geral já apontada essa distribuição "dispersiva” parece ligar-se também - a afirmação repousa em algumas observações colhidas durante as entrevistas qualitativas realizadas - ao receio dos empresários em limitarem suas atividades a um único setor, ou atividade econômica, e ficarem presos às oscilações conjunturais tão frequentes numa economia em desenvolvimento. A ideia de "repartir" os investimentos obedeceria, assim, àquela norma que manda "não colocar todos os ovos num único cesto". Tal procedimento tem, evidentemente, certas justificações objetivas no contexto do desenvolvimento brasileiro (onde sobressaem precariedade de capitais, oscilações de mercado, mudanças súbitas na política governamental, etc.), mas, num plano profundo, parece dizer respeito, sobretudo, à própria mentalidade empresarial, em sua concepção nem sempre racionalizada, o que se expressa, muitas vezes, na inexistência de uma estratégia global e bem definida de expansão nos negócios. Como quer que seja, no plano das consequências, essa dispersividade dos investimentos é provavelmente uma das causas determinantes da fraqueza econômica dos grupos nacionais vis-à-vis os grupos estrangeiros bilionários (Martins, I965: II2-II4).

Outros resultados importantes da pesquisa diziam respeito ao elevado índice de concentração das empresas brasileiras e ao fato de poucas serem empresas abertas, com títulos negociados na bolsa de valores. Bem diferente do que ocorria nos Estados Unidos, onde bastava ter, às vezes, até menos de $20 \%$ das ações para ter o controle da empresa, no Brasil, elas eram controladas por meio de "sólidas maiorias absolutas". Contudo, entre os resultados do trabalho, a forte relação que os grupos econômicos, industriais ou financeiros mantinham com o campo era especialmente surpreendente ao coordenador do projeto:

particularmente em São Paulo controlam empresas agrárias (agrícolas, agropecuárias, agromercantis, agroindustriais etc.), frequentes vezes desprovidas de qualquer conexão com as principais atividades do grupo [...] Importa observar 
que ainda em São Paulo, os grupos de capital estrangeiro parecem mais relacionados que os nacionais aos interesses agrários: segundo estimativas preliminares, 70\% deles mantêm firmas do tipo mencionado (Queiroz, I962: I68).

\section{UMA INTERVENÇÃO NOS DEBATES}

O projeto de pesquisa sobre os grupos econômicos contribuiu para formação de jovens, como mostram depoimentos de Gilberto Velho (I997, 20I2) e Alba Zaluar (2017) que dele participaram, e repercutiu notadamente nos meios acadêmicos paulistas e cariocas, intervindo nos debates:

Conceição Tavares, que havia escrito sobre a substituição de importações, frequentemente aparecia sem avisar e logo se formava um seminário. O mesmo acontecia com Florestan e com Fernando Henrique Cardoso que sempre apareciam para discutir. A pesquisa é citada em trabalhos da Conceição Tavares, de Florestan e sobretudo na tese de catedrático de FHC na USP, O empresário industrial e o desenvolvimento econômico (Maria Stella Amorim, e-mail, 20I8).

No início dos anos I960, José de Souza Martins se tornou assistente de Maurício Vinhas de Queiroz por recomendação de Fernando Henrique Cardoso:

Desde I963, por sugestão de Fernando Henrique, eu me envolvera também, numa enorme pesquisa de Maurício Vinhas de Queiroz sobre grupos econômicos no Brasil, realizada no Instituto de Ciências Sociais da Universidade do Brasil, hoje Universidade Federal do Rio de Janeiro. Maurício e seu grupo haviam organizado um imenso banco de dados sobre os grupos brasileiros e estrangeiros aqui no Brasil. A pesquisa entrava agora na fase de estudo qualitativo sobre as fontes de capital e o modo como se dera a acumulação originária de capital em cada um dos grupos multibilionários. Falou com Fernando Henrique sobre a pesquisa em São Paulo e ele propôs que fosse eu a fazer a pesquisa com mais alguém. Sugeri Antônio Carlos de Godoy, meu colega de turma e também aluno de Fernando Henrique. Escrevi doze pequenas monografias sobre o processo histórico de formação de grupos que me coube estudar. Eram meus relatórios de pesquisa. Mencionei-os a Florestan e disse-lhe que gostava particularmente da monografia sobre o conde Matarazzo. Ele me pediu que lhe trouxesse o texto. Leu e sugeriu que eu o desenvolvesse rapidamente e o transformasse numa dissertação de mestrado. Trabalhei intensamente (Martins, 2006: I45). ${ }^{2}$

Na época, o Centro de Sociologia Industrial e do Trabalho (Cesit), criado por iniciativa da cadeira de sociologia I da USP, ocupada então por Florestan Fernandes, protagonizava a guinada teórica e temática que vinha sendo almejada pelos jovens pesquisadores paulistas, vinculados a Florestan Fernandes, voltando seu foco de interesse para o estudo da sociedade de classes e do desenvolvimento. Um dos pesquisadores ocupados com aquela temática era Fernando Henrique Cardoso, que fazia pesquisa para sua tese de livre-docência, Empresário industrial e desenvolvimento econômico, defendida em I963. Em I967, quando o ICS encerrou suas atividades, Maurício Vinhas de Queiroz foi para a Universidade de São Paulo fazer o doutorado com Luís Pereira, assistente de Florestan, defendendo, em I972, tese intitulada Grupos econômicos e modelo brasileiro. 
Na realidade o debate mais candente no final dos anos I950 e início da década seguinte concentrava-se no papel da burguesia nacional no processo brasileiro de mudanças. Uma parte engajada dos intelectuais, sobretudo de esquerda, creditava à burguesia uma posição nacionalista e, ajuizava que ela poderia se unir aos trabalhadores e operários para liderar as reformas sociais. Segundo José de Souza Martins (2006: I46), a pesquisa dos grupos econômicos, coordenada por Maurício Vinhas de Queiroz, contrariava aquela tese e serviu de base para sustentar outras posições. Do mesmo modo, a tese de Fernando Henrique punha em xeque o papel do empresariado nacional na liderança das transformações sociais. No momento em que uma discussão fervorosa sobre a autonomia política e econômica do país circulava de norte a sul - na esfera pública, nos sindicatos urbanos e rurais, nos partidos, na imprensa, nos centros de cultura, na música, no cinema e no teatro -, os resultados das pesquisas sociológicas sobre o empresariado brasileiro e estrangeiro instalados no país guardaram uma visão cética relativamente ao papel da burguesia nacional no projeto de transformação do país. A pesquisa do ICS teve importante papel nesse diagnóstico.

A visão cética do panorama político brasileiro resultante do projeto se mostrou correta no decorrer dos acontecimentos políticos e econômicos do início da década de I960. Em meio à profunda crise econômica provocada pela rápida desaceleração do crescimento econômico e a tomada do poder pelo regime militar ditatorial, as expectativas sociais foram duramente revertidas. $\mathrm{O}$ livro de Luciano Martins (I968) Industrialização, burguesia nacional e desenvolvimento evidencia a brusca quebra das expectativas e previsões relativas à atuação da burguesia nacional no processo de desenvolvimento econômico autônomo. Ao retomar, em seu diagnóstico, os dados e as análises do referido projeto, sobretudo no capítulo "Empresário e mudança social: redimensionamento de um papel", o autor adverte que a realização do modelo de desenvolvimento nacional integrado passou a depender do surgimento de novos atores sociais e da superação dos limites estruturais do "capitalismo periférico", o que, segundo ele, dependia de tantas variáveis, que não se dispunha naquele momento (I968) de uma resposta (Martins, I968: I60-I6I).

\section{DUAS DÉCADAS DEPOIS}

Não seria possível neste breve registro de pesquisa relatar o que ocorreu com o Instituto de Filosofia e Ciências Sociais durante o regime ditatorial, sobretudo depois do Ato Institucional número 5, decretado em dezembro de I968. Houve um desmantelamento das atividades de ensino e pesquisa com a cassação de professores e alunos, com a prisão de muitos deles e assassinato de alguns. O IFCS, criado em I 967 com a Reforma Universitária e que funcionava na rua Marquês de Olinda, em Botafogo - em duas instalações: na frente uma bela casa que abrigava o Instituto de Pesquisa; atrás uma construção precária em que eram ministradas as aulas do curso de ciências sociais -, foi abruptamen- 
te transferido para o prédio da antiga Escola Nacional de Engenharia, no Largo de São Francisco no Centro da cidade. Sua biblioteca foi transportada em caminhões da Celurb (Companhia Estadual de Limpeza Urbana), os livros jogados em salas que só foram abertas em i980. Eram proibidas as reuniões com mais de três professores. O IFCS foi a instituição universitária federal mais atingida pelos órgãos de repressão da ditadura. Sobreviveu graças aos poucos professores jovens que lá permaneceram dando aulas, aos alunos combativos e aos funcionários que souberam lidar com aquela situação de exceção.

Só o entendimento desses anos difíceis revela a dimensão do "ressurgimento" da instituição no decorrer do regime democrático no país, permitindo avaliar a determinação com que o Instituto reconstruiu suas atividades em novos tempos. No que respeita à pesquisa, já em I 987 inicia-se, no âmbito das ciências sociais, o projeto Trabalhador Carioca. Produção e Reprodução da Classe Trabalhadora no Estado do Rio de Janeiro, cujo objetivo era investigar a especificidade dos trabalhadores urbanos cariocas: "o projeto abria um importante espaço de reflexão sobre o trabalho no Brasil, já que contrapunha o caso específico do Rio de Janeiro ao sempre estudado caso paulista, de certa forma paradigmático da industrialização e de seus efeitos sobre a economia e a sociedade brasileiras" (Abreu, Memorial, I996) A pesquisa contou com recursos da Financiadora de Inovação e Pesquisa (Finep) e no decorrer das atividades recebeu também apoio do CNPq.

Depois de duas décadas de regime autoritário, o debate político não se remetia mais ao papel da burguesia nas reformas, centrando-se antes na redemocratização do país e nos movimentos sociais. Quem mergulha na leitura de O trabalhador carioca. Estudos sobre trabalhadores urbanos do Estado do Rio de Janeiro, coletânea organizada por Alice Rangel de Paiva Abreu e Elina Gonçalves da Fonte Pessanha (I995) percebe que o projeto de pesquisa sobre a classe trabalhadora se configura em momento político, histórico e social bem distinto daquele dos Grupos Econômicos Multibilionários, no qual a memória, a perspectiva de gênero, a população infantil e jovem dessassistida, os movimentos sindicais e a violência vão paulatinamente tomar conta da agenda política, da esfera pública e da temática das ciências sociais. O projeto sobre o trabalhador carioca aborda pioneiramente alguns desses temas.

O estudo se dividia em dois grandes módulos. Um conjunto de pesquisas recuperava a memória do papel do Estado no desenvolvimento industrial do Rio de Janeiro, característica que em muito diferenciou aquele processo da formação industrial no estado de São Paulo. Os estudos sobre a indústria naval, a Fábrica Nacional de Motores e a Companhia Siderúrgica Nacional coordenados por Elina da Fonte Gonçalves Pessanha, José Ricardo Ramalho e Regina Lúcia de Moraes Morel, respectivamente, mostram como a intervenção do Estado na edificação da indústria repercutiu na configuração das classes trabalhadoras cariocas, em suas lutas e seu estilo de vida, ressaltando a natureza específica de seus movimentos reivindicatórios: 
Por um lado, o Rio tem um processo de industrialização regional que, contrariamente ao modelo de associação com o complexo exportador cafeeiro, se desenvolve vinculado ao comércio (principalmente importador) e ao capital financeiro. Por outro lado, a condição de capital da República e a decorrente proximidade com orgãos do governo federal acentuam o papel do Estado nesse processo.

[...] A forte presença do Estado no desenvolvimento industrial do Rio de Janeiro aprofundou as características próprias de uma classe trabalhadora altamente reivindicativa e com amplos setores capazes de explorar positivamente os espaços existentes de negociação com os demais setores da sociedade. Configura-se assim o chamado "trabalhismo à carioca", que se atualiza pela lógica das reciprocidades e alianças do populismo, ajudando a compor a vanguarda do movimento sindical pré64, que o golpe militar tão violentamente combateu (Abreu \& Pessanha, 1995: 7-8).

[...] os estudos sobre as empresas estatais mostram como o Estado no Brasil não só investiu no setor produtivo, mas também se preocupou com suas tarefas de gerência. A instalacão de regimes de produção estatais implicou uma fusão dos aparatos do Estado com os aparatos fabris (Buroway, 1985). A legislação industrial foi introduzida para regular e absorver conflitos de classe, e para facilitar o estabelecimento de diferentes formas de dominação sobre os trabalhadores.

A complexidade da resistência aparece com o surgimento e o crescimento da resistência coletiva através da ação sindical. Os diferentes tipos de resistência operária às estratégias empresariais do Estado apontam para diferentes níveis de percepcão do conflito com a gerência. Embora isto tenha causado desavenças entre militantes e não militantes, a diferença não desqualifica a resistência individual e coletiva, nem torna menos importante a reação às formas de dominação impostas (Ramalho, 1995: 57).

Não era apenas temática a diferença entre os dois projetos em foco. Enquanto o primeiro focalizava o papel dos empresários no desenvolvimento nacional, buscando saber das possibilidades de realização no futuro de uma sociedade moderna no Brasil, o segundo indagava a respeito do papel do Estado na edificação da indústria e do protagonismo político dos trabalhadores antes de 1964. A pesquisa sobre os trabalhadores cariocas prenuncia a grande virada na concepção moderna de tempo que durante décadas fundamentou as pesquisas nas ciências sociais brasileiras (Villas Bôas, 2006) ao substituir o diagnóstico do futuro pela registro da memória do passado. Além disso, em larga escala, percebe-se uma mudança metodológica que valoriza a voz dos atores sociais como nos mostra o depoimento de um trabalhador entrevistado por Regina Morel (1995: 63):

O Sr. G., um dos nossos primeiros entrevistados, morador do Bairro do Retiro como tantos outros aposentados, ao saber de nosso interesse em estudar a história dos ex-trabalhadores da CSN, presenteou-me, alguns dias após nosso primeiro contato, com a seguinte descrição de sua chegada, escrita de próprio punho, em duas folhas de caderno escolar:

"Setembro de 39: a Alemanha invadia a Polônia e em 8 de novembro de 1942 eu embarcava no trem da Rede Sul Mineira, no trem que vinha para Cruzeiro, que sai de Passa Quatro às 9 horas da manhã. Quando deu 16 horas, estava em Volta Redonda. 
Uma estaçãozinha da Central do Brasil, a I2 quilômentros de Barra Mansa, sendo Volta Redonda distrito desta. Arranjei emprego numa firma empreitera e em I I de fevereiro de 1942 fui ao escitório da CSN procurar para me fichar. Fiz experiência e fui matriculado. Trabalhei três anos das 6 da manhã às I 8 horas da tarde. Em Volta Redonda quase nada existia. Estavam sendo construídos os escritórios, os alojamentos, tudo de madeira, até o Hospital. Milhares de homens. Todos estavam na luta. Era dia e noite sem parar, um verdadeiro formigueiro; caminhões, homens, máquinas e tratores [...] Dez meses depois, a 8 de novembro de 1942, o governo declara de interese militar a usina de Volta Redonda. Fiquei mobilizado. Trabalhei na construcão e instalacão de água e esgoto em algumas mil casas e em janeiro de I949 fui para a usina sendo classificado como mecânco de manutencão."

E, para concluir, é com satisfação que nos conta:

"Eu fui lutando, fui lutando... formei um casal de universitários: uma professora e um engenheiro industrial metalúrgico, formado em I975" (Morel, I995: 63).

Outro importante conjunto de estudos tinha o objetivo de pesquisar as mudanças relativas à segmentação do mercado de trabalho, pondo em foco a questão da marginalidade e da inserção diferenciada de homens e mulheres a partir de uma perspectiva de gênero e da infância. Nessa direção, as pesquisas desvendam as ambiguidades da subcontratação e seus efeitos no desenvolvimento profissional dos trabalhadores, evidenciando as diferenças de gênero; descrevem os deslocamentos e os meandros das ocupações femininas ao longo de algumas décadas do XIX ao XX e mostram as consequências do trabalho infantil na fábrica. Desse módulo participaram Alice Rangel de Paiva Abreu, Bila Sorj, Rosilene Alvim, Paola Cappellin e Luiz Antonio Machado.

Os trechos a seguir versam, primeiro, sobre o espaço produtivo feminino, destacando as especificidades do trabalho das mulheres em regime de subcontratação; segundo, sobre as mudanças ocorridas nas ocupações femininas no mercado de trabalho de 1872 a I980:

A producão realizada no domínio doméstico incorpora um conjunto de crenças, significados e práticas associados ao mundo feminino e à divisão sexual das tarefas domésticas. De fato a separação espacial, temporal e funcional entre trabalho industrial e vida familiar acontece, apenas, para o grupo masculino, enquanto que para as costureiras estas esferas de atividades se interpenetram, exigindo uma permanente adaptação entre elas. Costurando ora na sala, ora na cozinha ou quarto, a geografia da produção molda-se ao ritmo dos rituais familiares. O tempo da producão se adapta e, por vezes, interfere no tempo dedicado aos afazeres domésticos e a diferenciação das funções produtivas e do trabalho doméstico é fracamente realizada, à medida que costurar e cuidar dos filhos, de doentes, e, ainda, vigiar a casa, são tarefas realizadas simultaneamente (Abreu \& Sorj, I995: I4I).

A taxa de mão de obra feminina operária reconstruida sobre a base dos censos no Brasil desenha-se graficamente como uma curva $\bigcup$. Isto é, desde o período de mais alta inserção feminina (fim do século XIX) até a década de I950, sua participação declina rapidamente. Nos últimos anos, de I970 a I980, observa-se uma recuperacão sem por isso alcançar a alta taxa de sua participação registrada em 1872 (Capellin, I995: IOI-IO2). 
O censo de 1872 registra, para o Estado do Rio de Janeiro, ao lado da incorporação das operárias nos estabelecimentos industriais, o grande conjunto de costureiras (21.536) que é numericamente superior ao total de operários. Devem ser incluídas também outras ocupações: as parteiras (que representam Io\% do pessoal da saúde), as artistas $(5 \%)$, as professoras $(38 \%)$, as comerciárias $(2 \%)$, as trabalhadoras dos servicos domésticos (68\%), além das mulheres (36\%) que atuam diretamente na agricultura (Capellin, I995: I05).

Além da ênfase na memória e na escolha de temas e metodologias inovadoras, as pesquisas sobre as classes trabalhadoras descortinam o processo de especialização agudo que vinha ocorrendo nas ciências sociais, de forma acelerada, a partir da Reforma Universitária de I968 e da implantação do sistema nacional de pós-graduação. Tanto assim que uma das referências importantes dos pesquisadores, ao falar sobre sua iniciativa, é o sucesso do Grupo de Trabalho Processo de Trabalho e Reivindicações Sociais, da Associação Nacional de Pós-Graduação em Ciências Sociais (Anpocs), criado em I984 e que os entusiasmou de tal forma, a ponto de solicitar recursos à Finep. Se num primeiro momento, a agenda temática das ciências sociais estava vinculada a questões nacionais como a modernidade e o desenvolvimento do país, o período de redemocratização aprofundou a escolha de temas específicos e incrementou uma segunda e decisiva fase da institucionalização das ciências sociais no país.

Dividíamos [essas] "descobertas" de pesquisa com outras, de colegas de todo o país, reunidos num novo Grupo de Trabalho da Anpocs - o GT Processo de Trabalho e Reivindicações Sociais, criado em I984 [...]. Ali estavam, entre muitos outros, a sempre lembrada Beth Lobo, Márcia Leite, Laís Abramo, Helena Hirata, Nadia Castro, Antonio Sérgio Guimarães, Iram Rodrigues, Amelia Cohn, José Sérgio Leite Lopes, Magda Neves, Leila Blass, Michael Hall, Christian Azaiz, Leda e Malu Gitahy, Sonia Guimarães, Ricardo Antunes, Andre Laino, Afonso Fleury, Edna Castro. O grupo funcionava paralelamente ao tradicional GT de Sindicalismo. Muitos de nós estudávamos também sindicalismo, mas o novo grupo enfatizava a ligação entre o que era vivido nos locais de trabalho e a construção das demandas trabalhadoras que o sindicato podia ou não absorver - daí as "oposições sindicais" -, e isso nos parecia fundamental naquele momento de afirmação do protagonismo de classe e da crescente autonomia de seus projetos - e dos nossos - para a restauração da democracia em nosso país (Pessanha, 2015: 23).

O projeto passou a funcionar na sala 4I 8 do prédio do IFCS. "Reformamos a sala 4I8 - a das bancadas azulejadas - dividimos e equipamos as salas, e instalamos uma linha de telefone, luxo raro na época" (Pessanha, 2015: I8). Luxo era mesmo todo o conjunto de salas abrigado na 4I8, num momento em que o IFCS apenas começava a dar seus primeiros passos para reordenar a "casa" que lhe fora destinada na ditadura, investindo no prédio e na sua produção acadêmica. A pesquisa sobre os trabalhadores, afirma Alice Abreu (I996), foi o embrião de um dos grupos de pesquisa mais fortes da pós-graduação do IFCS, consolidando um espaço institucional de debate e contribuindo de forma decisiva para a crescente qualidade do curso de mestrado e mesmo da graduação, congregando inúmeros bolsistas de iniciação científica. ${ }^{3}$ 
Ao iniciar este registro de memória, ponderei não ser simples encontrar uma medida para avaliar os efeitos de uma prática intelectual de 80 anos no âmbito das ciências sociais no IFCS. Certamente estudos mais aprofundados poderão aquilatar a importância daquelas atividades de pesquisa e formação de jovens. Ao concluir estas anotações, contudo, vale dizer que um primeiro passo, naquele sentido, é questionar a descontinuidade provocada pelos anos de ditadura, e à revelia das interpetações correntes, que seguem um único modelo institucional-padrão, acolher a história singular do ICS e do IFCS. Só assim é possível insistir na busca e na leitura da documentação que registra aquelas atividades e descobrir a vitalidade própria de diferentes gerações de cientistas sociais que não se curvaram diante dos obstáculos. Que a comemoração dos 80 anos das ciências sociais no IFCS seja um marco para a inauguração de novos estudos sobre sua memória.

Recebido em IO/I 2/20I8 | Aprovado em I5/I/20I9

Glaucia Villas Bôas é professora titular do Programa de PósGraduação em Sociologia e Antropologia da UFRJ e do Programa de Pós-Graduação em Artes, Cultura e Linguagens da UFJF. Dedica sua docência e pesquisa à teoria sociológica e à sociologia da cultura. Entre livros e artigos publicados, destacam-se a organização de Arte e vida social. Pesquisas recentes no Brasil e na França (20I6) e Georg Simmel. Ensaios de estética sociológica (2016). 


\section{NOTAS}

I Agradeço gentilmente a Maria Stella Amorim a presteza com que respondeu mensagem que lhe enviei pedindo informações sobre o projeto.

2 A dissertação de mestrado de José de Souza Martins, Empresário e empresa na biografia do conde Matarazzo, foi publicada em I967 na série Monografias do ICS e, em segunda edição em I973 pela Editora Hucitec, em São Paulo, com o título Conde Matarazzo. O empresário e a empresa.

3 Paralelamente à realização do projeto sobre as classes trabalhadoras apoiado pela Finep, foi criado o Laboratório de Pesquisa Social e logo o seu Programa de Iniciação Científica, financiado pela Fundação Ford e coordenado por Yvonne Maggie com a participação de cerca de 20 professores. O objetivo do LPS era a melhoria da graduação em ciências sociais pela inserção dos estudantes em projetos de pesquisa. Os dois projetos foram decisivos para a construção da Pós-Graduação em Sociologia e Antropologia e para a diminuição da evasão e melhoria da graduação em ciências sociais.

\section{REFERÊNCIAS BIBLIOGRÁFICAS}

Abreu, Alice Rangel de Paiva \& Pessanha, Elina da Fonte Gonçalves (orgs.). (I995). O trabalhador carioca. Estudos sobre os trabalhadores urbanos do estado do Rio de Janeiro. Rio de Janeiro: Editora JC.

Abreu, Alice Rangel de Paiva \& Sorj, Bila. (I995). Subcontratação e relação de gênero na indústria de confecção. In: Abreu, Alice Rangel de Paiva \& Pessanha, Elina da Fonte Gonçalves (orgs.). O trabalhador carioca. Estudos sobre os trabalhadores urbanos do estado do Rio de Janeiro. Rio de Janeiro: Editora JC.

Abreu, Alice Rangel de Paiva. (I996). Memorial. IFCS/UFRJ (mimeo).

Abreu, Alice Rangel de Paiva \& Pessanha, Elina da Fonte Gonçalves. (I995). Apresentação. In: Abreu, Alice Rangel de Paiva \& Pessanha, Elina da Fonte Gonçalves (orgs.). O trabalhador carioca. Estudos sobre os trabalhadores urbanos do estado do Rio de Janeiro. Rio de Janeiro: Editora JC, p. 7-II. 
Amorim, Maria Stella. (I999). Costa Pinto e a Missão Sociológica. In: Maio, Marcos Chor \& Villas Bôas, Glaucia (orgs.). Ideais de modernidade e sociologia no Brasil. Ensaios sobre Luiz de Aguiar Costa Pinto. Porto Alegre: Ed. UFRGS, p. 23-38.

Cappellin, Paola. (I995). Ocupações femininas. Reconstruindo as relações de gênero no mercado de trabalho regional. Rio de Janeiro, I972-I980. In: Abreu, Alice Rangel de Paiva \& Pessanha, Elina da Fonte Gonçalves (orgs.). O trabalhador carioca. Estudos sobre os trabalhadores urbanos do estado do Rio de Janeiro. Rio de Janeiro: Editora JC, p. 97I37.

Martins, José de Souza. (2006). Entrevista. In: Bastos, Elide Rugai; Abrucio, Fernando; Loureiro, Maria Rita \& Rego, José Marcio (orgs.). Conversas com sociólogos brasileiros. São Paulo: Ed. 34, p. I35-160.

Martins, Luciano. (1968). Industrialização, burguesia nacional e desenvolvimento. Rio de Janeiro: Editora Saga.

Martins, Luciano. (1965). Grupos bilionários nacionais (I a 4 bilhões). Revista do Instituto de Ciências Sociais, 2/I, p. 79-II6.

Morel, Regina L. de Moraes. (I995). História incorporada e identidade coletiva entre trabalhadores aposentados da Companhia Siderúrgica Nacional. In: Abreu, Alice Rangel de Paiva \& Pessanha, Elina da Fonte Gonçalves (orgs.). O trabalhador carioca. Estudos sobre os trabalhadores urbanos do estado do Rio de Janeiro. Rio de Janeiro: Editora JC, p. 6I-96. Pessanha, Elina da Fonte Gonçalves. (20I5). Memorial. IFCS/UFRJ (mimeo).

Queirós, José Antônio Pessoa de. (1965). Grupos bilionários estrangeiros (de I a 4 bilhões). Revista do Instituto de Ciências Sociais, 2/I, p. II7-I86.

Queiroz, Maurício Vinhas de. (1965). Grupos multibilionários. Revista do Instituto de Ciências Sociais, 2/I, p. 47-77. Queiroz, Maurício Vinhas de. (I962). Os grupos econômicos no Brasil. Revista do Instituto de Ciências Sociais, I/2, p. I57-I68.

Ramalho, José Ricardo. (I995). Empresas estatais de primeira geração: formas de gestão e ação sindical. Abreu, 
Alice Rangel de Paiva \& Pessanha, Elina da Fonte Gonçalves (orgs.). O trabalhador carioca. Estudos sobre os trabalhadores urbanos do estado do Rio de Janeiro. Rio de Janeiro: Editora JC, p. 37-6o.

Revista do Instituto de Ciências Sociais. (I962). Seção Noticiário. I/I, p. 273-274.

Velho, Gilberto. (20I2). Entrevista. In: Trindade, Hélgio. Ciências sociais no Brasil. Diálogos com mestres e discípulos. Brasília: Anpocs/Liber Livro Editora, p. 299-317.

Velho, Gilberto. (I997). Maurício Vinhas de Queiroz (I92 II996). Anuário Antropológico, I996. Rio de Janeiro: Tempo Brasileiro, p. 283-285.

Villas Bôas, Glaucia. (2006). Mudança provocada. Rio de Janeiro: Ed. FGV.

Zaluar, Alba Maria. (20I7). Depoimento. Rio de Janeiro: CPDOC/Fundação Getúlio Vargas. 


\section{ANOS DE CIÊNCIAS SOCIAIS NA UFRJ: RELEMBRANDO O PIONEIRISMO DOS PROJETOS GRUPOS ECONÔMICOS (1962) E TRABALHADORES CARIOCAS (1987) \\ Resumo}

$\mathrm{Na}$ ocasião em que as ciências sociais completam 80 anos de existência na UFRJ, este artigo comemora dois projetos de pesquisa pioneiros, realçando tanto sua repercussão nos debates sobre os temas do capital e do trabalho quanto seus efeitos na construção institucional das ciências sociais no Rio de Janeiro. A primeira dessas pesquisas, realizada no Instituto de Ciências Sociais na década de I960, sob a coordenação de Maurício Vinhas de Queiroz, identificou pela primeira vez os grupos econômicos brasileiros e estrangeiros instalados no país; a segunda, sob a coordenação de Alice Rangel de Paiva Abreu e Elina Gonçalves da Fonte Pessanha, com início no final de I980, revelou características do protagonismo político dos trabalhadores e da participação do Estado em grandes empresas além de abordar questões de gênero e juventude.

\section{YEARS OF SOCIAL SCIENCES AT UFRJ: REMEMBERING} THE PIONEERING RESEARCH OF THE ECONOMIC GROUPS (1962) AND RIO WORKERS (1987) PROJECTS conducted at the former Institute of Social Sciences in the I96os under the supervision of Maurício Vinhas de Queiroz, identified for the first time the Brazilian and foreign economic groups established in the country. The second project, directed by Alice Rangel de Paiva Abreu and Elina Gonçalves da Fonte Pessanha, started in the late I980s with a broad agenda: to disclose the political protagonism of workers, and State intervention ranging into enterprises, as well as to address gender and youth-related questions.

\section{Palavras-chave}

Ciências sociais;

Universidade Federal do Rio de Janeiro;

memória;

projetos de pesquisa;

história das ciências sociais no Rio de Janeiro.

\section{Keywords}

Social sciences;

Federal University of

Rio de Janeiro;

memory;

research projects;

history of social sciences in Rio de Janeiro. 